\title{
The Conformational Change with Temperature of End Group Sequences of Low Molecular Weight Polyethylene
}

\author{
Takahiko NAKAOKI, Ryozo KITAMARU, ${ }^{*}$ \\ Rufina G. Alamo, ${ }^{*}$ Wei T. HUANG, ${ }^{*}$ a and Leo MANDELKERN $* * *$ \\ Faculty of Science and Technology, Ryukoku University, Seta, Otsu 520-2194, Japan \\ * 11 Hanazono Enjyoji, Ukyo-ku, Kyoto 616-8027, Japan \\ * * Department of Chemical Engineering, Florida Agricultural and Mechanical University-Florida State \\ University College of Engineering, 2525 Pottsdamer Street, Tallahassee, FL 32310-6046, U. S. A. \\ *** Department of Chemistry and Institute of Molecular Biophysics, \\ Florida State University, Tallahassee, FL 32306-4380, U. S. A.
}

(Received April 24, 2000; Accepted June 28, 2000)

\begin{abstract}
A detailed analysis of the temperature dependent solid state carbon-13 spectrum of a low molecular weight polyethylene fraction, that was isothermally crystallized in extended chain forms is reported. The observed resonances were assigned to specific carbons and the ${ }^{13} \mathrm{C}$ spin-lattice relaxation times, $T_{1 \mathrm{C}}$, for the internal and $\alpha$-methylene carbons as well as the end-group methyl carbons were determined. Based on the analysis, and an accompanying thermogram, obtained by differential scanning calorimetry, it was concluded that conformational disordering of the chain-end sequence takes place at temperatures well below the fusion range. This conclusion is in accord with the standard model that has been taken for an equilibrium crystallite.

KEY WORDS Linear Polyethylene / Extended Chain Crystal / Molecular End Methyl Carbon / $\alpha$ Methylene Carbon / End-Group Pairings / Flory's Equilibrium Theory / Extremely Narrowing Condition /
\end{abstract}

The crystallization of the $n$-alkanes differs from the low molecular weight linear polyethylenes in one important aspect. In the former case, because of the uniformity in chain length, molecular crystals can be formed and the end-groups can be paired from one crystalline layer to another. However, in the polyethylenes, as well as other polymers, no matter how well the sample is fractionated the molecular weights are not uniform and a regular register of the end-group pairings cannot be achieved. Pre-melting, i.e., disordering of the end-group sequences, prior to complete melting has been established in the $n$-alkanes by a variety of experimental techniques. ${ }^{1}$ Since complete melting of the $n$-alkane and of polyethylenes of comparable molecular weight have been found to occur at the same temperature ${ }^{2}$ it can be concluded that the end-sequences are also disordered in the polymers.

However, it is yet to be established at what point in the fusion process this type of pre-melting takes place in the polymers. Although of interest in itself, this type of chain-end disordering is an inherent part of Flory's equilibrium theory of melting of polymers, ${ }^{3}$ and hence is of basic theoretical interest. This part of the theory has not as yet received a direct assessment. It should be noted at this point that the Flory-Vrij analysis is for chains of finite and uniform length. It does not apply to polymer fractions, except in the limit of infinite molecular weight. Unfortunately, it has on occasion been incorrectly applied to polymer fractions. ${ }^{4}$

Solid-state ${ }^{13} \mathrm{C}$ nuclear magnetic resonance (NMR) is a very suitable method to assess the changes, if any, in the end-group structure as a function of temperature. This type of study is reported in the present work, focussing on the behavior of a low molecular weight polyethylene fraction, crystallized in extended chain form. It is necessary in this endeavor to assign the resonances to specific carbon atoms and to also determine the appropriate, corresponding relaxation times. With this information, the changes in the nmr spectra with temperature can be related to the fusion process.

\section{EXPERIMENTAL}

\section{Samples}

The sample used in this work was a low molecular weight linear polyethylene, designated as PE 1000. It was purchased from the Petrolite Corporation. The number and weight average molecular weights are, respectively 1138 and 1263 , and the ratio is: $\bar{M}_{\mathrm{w}} / \bar{M}_{\mathrm{n}}=1.11$. This sample was crystallized from the melt at $110^{\circ} \mathrm{C}$ for 1 day and formed extended chain crystallites.

\section{${ }^{13} \mathrm{C} N M R$}

The ${ }^{1} \mathrm{H}$ dipolar decoupling/magic angle spinning (DD/ MAS) ${ }^{13} \mathrm{C}$ nmr measurements, with or without ${ }^{1} \mathrm{H}^{-13} \mathrm{C}$ cross-polarization (CP), were carried out at a field strength of $4.7 \mathrm{~T}$ with a Bruker MSL 200 spectrometer. The ${ }^{13} \mathrm{C}$ resonant frequency was $50.3 \mathrm{MHz}$, and the $\mathrm{B}_{1}$ strength used was $65 \mathrm{kHz}$ for both ${ }^{13} \mathrm{C}$ and ${ }^{1} \mathrm{H}$. The MAS was carried out at $3 \mathrm{kHz}$. The detailed procedure that was followed will be described subsequently in the appropriate place. The chemical shift was expressed for tetramethylsilane (TMS), based on the resonant line of the carbon of the carbonyl group of glycine, whose chemical shift is $176.03 \mathrm{ppm}$ from TMS. Temperature calibration was carried out following a method similar to the one developed by Kaplan et al. ${ }^{5}$ for a VT/MAS probe. In this method the calibration was performed using the difference between two ${ }^{1} \mathrm{H}$ resonant lines of $\mathrm{CH}_{2}$ and $\mathrm{OH}$ of ethylene glycol. 


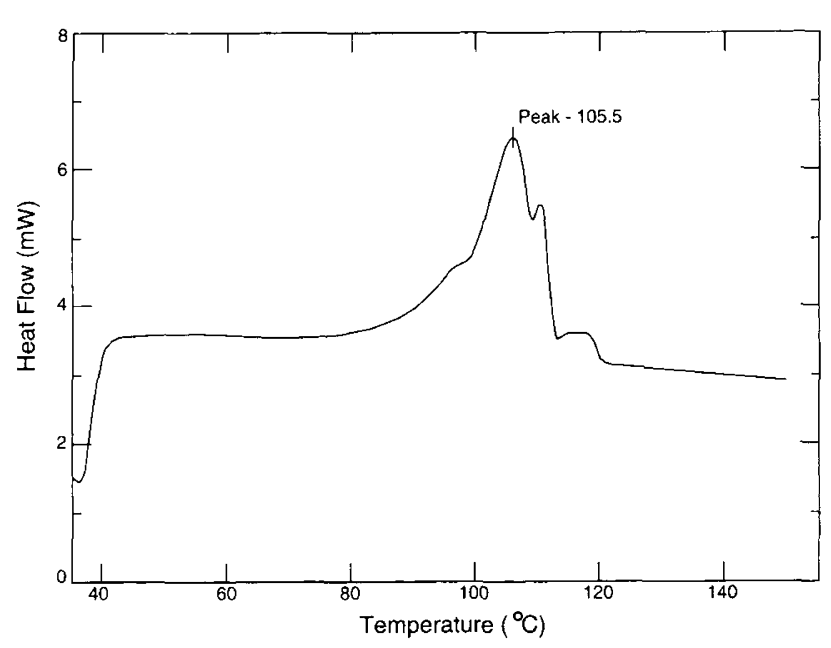

Figure 1. Melting thermogram obtained by differential scanning calorimetry for linear polyethylene, PE 1000, $M_{\mathrm{w}}=1263, M_{\mathrm{n}}=$ 1138 , crystallized at $110^{\circ} \mathrm{C}$ for 1 day.

\section{Differential Scanning Calorimetry}

The thermal properties of the low molecular weight polyethylene were obtained by differential scanning calorimetry (DSC) using a Perkin-Elmer differential scanning calorimeter (DSC) 7 operating at a heating rate of $10^{\circ} \mathrm{C} \mathrm{min}{ }^{-1}$. Approximately $1.5 \mathrm{mg}$ was used. The calorimeter was calibrated with indium for temperature and thermal lag effects. The thermogram is shown in Figure 1. A main endotherm, centered at $105.5^{\circ} \mathrm{C}$, indicates the formation of extended-type crystallites. Some fractionation also took place during the crystallization process as indicated by a small $\left(\sim 10 \mathrm{~J} \mathrm{~g}^{-1}\right)$ endotherm at $\sim 117^{\circ} \mathrm{C}$. Molecular fractionation is known to occur during the crystallization of low molecular weight polyethylenes. $^{6}$

\section{RESULTS AND DISCUSSION}

\section{CP/MAS Spectrum}

The CP/MAS spectrum of PE 1000 was initially obtained at room temperature using a $45^{\circ}$ pulse sequence. The recycle time and contact times were fixed as $20 \mathrm{~s}$ and $1 \mathrm{~ms}$ respectively. These values were chosen based on the $\mathrm{T}_{1 \mathrm{H}}$ of $7.2 \mathrm{~s}$. Figure 2 shows the CP/MAS ${ }^{13} \mathrm{C} \mathrm{nmr}$ spectrum. Here the Lorentz/Gauss transformed spectrum is shown in order to distinguish between the contribution of the individual carbons. The resonant lines assigned to molecular end methyl, neighboring $\alpha$ and internal methylene carbons can be distinctly seen. An upfield shoulder can be seen at ca. $30 \mathrm{ppm}$ in the resonance of the internal methylene carbon that is centered at 32.4 ppm. This shoulder can be assigned to the internal methylene carbon in a non-crystalline environment, similar to the assignment made in crystalline linear polyethylene of higher molecular weights. ${ }^{7}$ In high molecular weight linear polyethylene, the noncrystalline methylene carbons were found to be distributed between two phases, i.e., in the noncrystalline amorphous phase and in the crystalline-amorphous interphase. ${ }^{7}$ However, in the low molecular weight extended crystals, that are studied here, the non-crystalline content corresponds to just a few carbons that are adjacent to the molecular

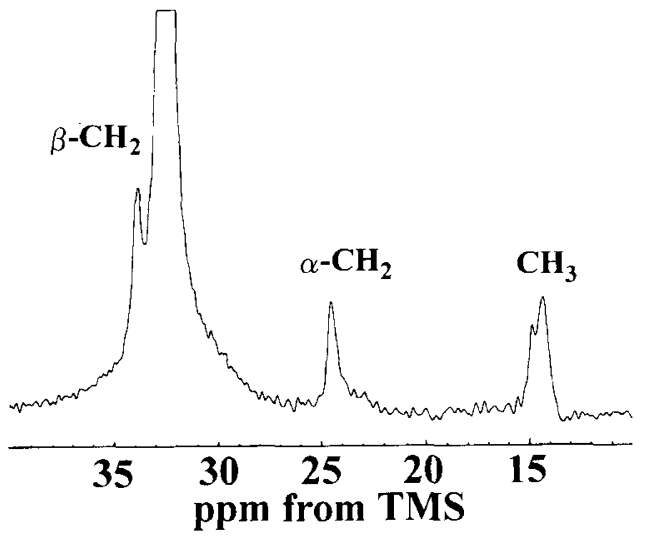

Figure 2. CP/MAS spectrum of PE 1000 at room temperature. The Lorentz/Gauss transformed spectrum is shown.

ends. Thus, this region is not expected to conform to the classical interphase and amorphous phases but rather to a more diffuse structure where the end groups and noncrystalline adjacent carbons are found. Because crosspolarization (CP) efficiency diminishes in this region, the characterization of this phase was attempted by DD/ MAS spectra as will be detailed later.

In Figure 2, in addition to the resonance of the inner $\mathrm{CH}_{2}$ at $32.4 \mathrm{ppm}$, a sharp resonance is found centered at $33.8 \mathrm{ppm}$ which could be assigned to the $\beta$-methylene carbons. ${ }^{8}$ It should be noted that this is also the region of resonance of inner $\mathrm{CH}_{2}$ of the monoclinic phase of polyethylene. Hence, initially, we could not neglect a possible contribution from this phase to the CP/MAS spectrum. wide-angle X-Ray Scattering (WAXS) diffractograms were not obtained for the sample analyzed. However, previous studies of a similar low molecular weight polyethylenes, crystallized from the melt at $110^{\circ} \mathrm{C}$, indicate the preferential development of the orthorhombic phase. ${ }^{1,9}$ The information about the $\beta$-methylene carbons is important to help ascertain the molecular motion in the vicinity of the molecular ends. However, due to the diminished intensity of this resonance and the difficulty in deconvoluting any possible monoclinic contribution, we have not studied this resonance in detail.

Two overlapping resonances corresponding to the methyl group are found in the range of $13-16 \mathrm{ppm}$, i.e., a downfield resonance centered at $c a .15 \mathrm{ppm}$ and upfield one centered at $14.4 \mathrm{ppm}$. This type of splitting was reported by Pérez and VanderHart ${ }^{10}$ and by Russell et $a l^{11}$ for low molecular weight polyethylene. The downfield and upfield lines were assigned by Pérez and VanderHart ${ }^{10}$ to methyl carbons in a crystalline and noncrystalline environments, respectively. It was reported by VanderHart and Pérez ${ }^{12}$ that the $\alpha$-methylene carbon resonance, found in the vicinity of $25-23 \mathrm{ppm}$, consists of downfield and upfield components that are assigned respectively to these carbons in the crystalline and noncrystalline environment. However, in Figure 2 the upfield line of the $\alpha-\mathrm{CH}_{2}$ resonance is only present as a diffuse shoulder of the sharp downfield line centered at $c a .24 .5 \mathrm{ppm}$. A detailed description of the distribution of $\alpha$-methylene carbons between the down and upfield lines will be presented later when interpreting partially relaxed spectra of this polymer at higher temperatures. 
Table I. $\quad T_{1 \mathrm{C}}$ of internal, $\alpha$-methylene carbons and methyl carbons at room temperature, $50^{\circ} \mathrm{C}$ and $80^{\circ} \mathrm{C}$

\begin{tabular}{|c|c|c|c|c|c|c|}
\hline \multirow[b]{2}{*}{ Temperature/ $/ \mathrm{C}$} & \multicolumn{6}{|c|}{$T_{1 \mathrm{C}}$} \\
\hline & Internal & Crystalline & Methylene & $\begin{array}{l}\alpha \text {-meth } \\
\text { Downfield }\end{array}$ & $\begin{array}{l}\text { ylene }{ }^{b} \\
\text { Upfield }\end{array}$ & $\begin{array}{c}\text { Methyl } \\
-\mathrm{c}\end{array}$ \\
\hline Room & $1500 \mathrm{~s}(0.48)$ & $390 \mathrm{~s}(0.39)$ & $32 \mathrm{~s}(0.13)^{\mathrm{a}}$ & $3.9 \mathrm{~s}$ & - & $1.6 \mathrm{~s}$ \\
\hline $50^{\circ} \mathrm{C}$ & \multicolumn{3}{|c|}{-not measured- } & $3.7 \mathrm{~s}$ & $1.2 \mathrm{~s}$ & $2.7 \mathrm{~s}$ \\
\hline $80^{\circ} \mathrm{C}$ & $169 \mathrm{~s}$ & $7.1 \mathrm{~s}$ & $0.5 \mathrm{~s}$ & $2.5 \mathrm{~s}$ & $3.2 \mathrm{~s}$ & $4.4 \mathrm{~s}$ \\
\hline
\end{tabular}

${ }^{a}$ Values in parenthesis indicate the fractional intensity of each $T_{1 \mathrm{C}}$ component. 'The downfield and upfield $T_{1 \mathrm{C}}$ 's of $\alpha$ methylene were obtained by lineshape deconvolution of each spectrum in the course of the saturation-recovery. ${ }^{c}$ Down and upfield resonances were not distinguished.

$T_{1 C}$ of Internal and $\alpha$-Methylene and Molecular End Methyl Carbons

The ${ }^{13} \mathrm{C}$ spin-lattice relaxation time, $T_{1 \mathrm{C}}$, of the internal methylene and $\alpha$-methylene carbons and the methyl carbon was determined at room temperature and at $50^{\circ} \mathrm{C}$ and $80^{\circ} \mathrm{C} . T_{1 \mathrm{C}}$ for the internal methylene carbon was obtained by the CPT 1 pulse sequence developed by Torchia, ${ }^{13}$ using a contact time of $1 \mathrm{~ms}$. Those for the $\alpha$ methylene and methyl carbons were obtained by a standard saturation recovery pulse sequence. The results are summarized in Table I.

Internal Methylene. Figure 3 shows the magnetization decay of the peak intensity for internal methylene resonance line at $32.4 \mathrm{ppm}$ in CPT 1 pulse sequence. It behaves similarly to that for polyethylenes of higher molecular weight. ${ }^{7,14,15}$ As is shown in the figure three exponential terms, i.e., three different $T_{1 \mathrm{C}}$ 's, are needed to properly fit the decay. The three different $T_{1 C}$ 's are associated with the three regions of the phase structure that have different relaxation properties. The value of the longest $T_{1 \mathrm{C}}, 1500 \mathrm{~s}$, is higher than the value of $900 \mathrm{~s}$ reported by Axelson et al. ${ }^{16}$ for the same polymer slowly cooled from the melt. The difference in the $T_{1 \mathrm{C}}$ values can be related to the different crystallization procedures that were used. The longest $T_{1 \mathrm{C}}$ is assigned to the internal crystalline methylene carbons with no or very minor influence from the motion of methylene carbons in the noncrystalline region and molecular end groups. The medium and shortest $T_{1 \mathrm{C}}$ 's can be assigned to the crystalline methylene carbons that belong to structures with shorter stem lengths. The mass fraction of each $T_{1 \mathrm{C}}$ component in the total crystalline component was also estimated by the magnetic relaxation in Torchia's CPT 1 pulse sequence, with use of the relation

$$
\begin{aligned}
& I(t) / I(0)=f_{1500} e^{-t / 1500}+f_{390} e^{-t / 390}+f_{32} e^{-t / 32} \\
& \text { with } f_{1500}+f_{390}+f_{32}=1
\end{aligned}
$$

where $I(t)$ is the magnetization at time $t$ in CPT 1 pulse sequence and $I(0)$ is the initial value, i.e., two times the magnetization obtained by the cross polarization, and $f_{1500}, f_{390}, f_{32}$ are the mass fractions of the components of $1500 \mathrm{~s}, 390 \mathrm{~s}$, and $32 \mathrm{~s}$ of $T_{1 \mathrm{C}}$. These mass fractions obtained are also listed with $T_{1 \mathrm{C}}$ values in Table I. These value may be somewhat influenced by the contact time because of different CP efficiency. Nevertheless, since the shortest $T_{1 \mathrm{C}}$ is still as long as $32 \mathrm{~s}$, the difference of

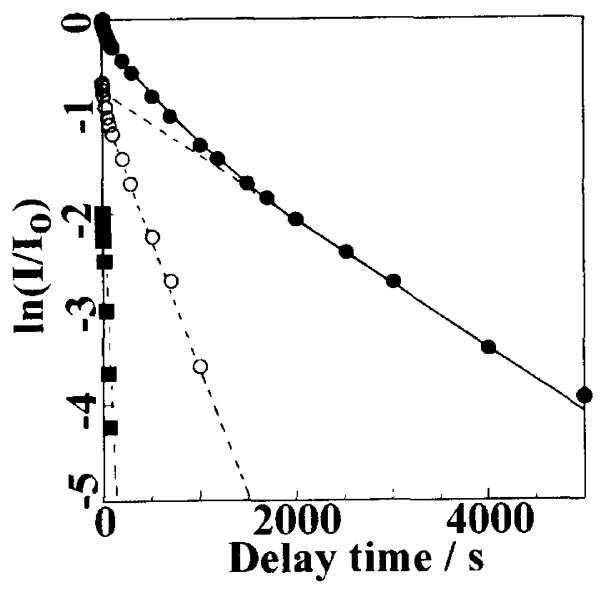

Figure 3. Semi logarithmic decay of the peak intensity for crystalline resonance line at $32.4 \mathrm{ppm}$ in CPT 1 pulse sequence. The upper solid line with solid circles indicates the experimental data. The dashed line attached indicates the decay for the component with $T_{1 \mathrm{C}}$ of $1500 \mathrm{~s}$. The open circles indicate the values that were obtained by subtraction of the contribution from $1500 \mathrm{~s} T_{1 \mathrm{C}}$ component, and the dotted line attached is the decay for $T_{1 \mathrm{C}}$ of $390 \mathrm{~s}$. The squares indicate the values that were obtained by subtraction of the contributions from the components with $T_{1 \mathrm{C}}$ 's of $500 \mathrm{~s}$ and 390 $\mathrm{s}$ and the dotted line attached is the decay for $T_{\mathrm{IC}}=32 \mathrm{~s}$.

CP efficiency is not sufficiently enhanced so as to significantly affect the results. These values will be used later for analyses of the phase structure.

Molecular End Methyl Carbon. The $T_{1 \mathrm{C}}$ of $1.6 \mathrm{~s} \mathrm{ob-}$ tained at room temperature for the methyl carbon is in a range similar to the values reported for the methyl carbon of crystalline $n$-alkanes and low molecular weight polyethylenes. Russell et al. ${ }^{11}$ reported $T_{1 \mathrm{C}}$ of $1.9 \mathrm{~s}$ and $3.0 \mathrm{~s}$, that were obtained at $50.3 \mathrm{MHz}$ of ${ }^{13} \mathrm{C}$ resonance frequency, similarly to this work, for the upfield reso-

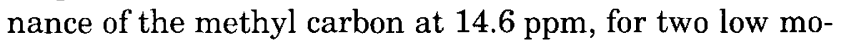
lecular weight polyethylenes. A $T_{1 \mathrm{C}}$ of $1.7 \mathrm{~s}$ was reported for the downfield line of the methyl carbon at $15.2 \mathrm{ppm}$ for one of the polymers. Before carrying out further analysis, it is important to know whether the $T_{1 \mathrm{C}}$ of the methyl carbons under consideration are in the range where the motional narrowing condition $\left(\omega_{\mathrm{c}}{ }^{2} \tau_{\mathrm{c}}{ }^{2}<<1\right)$ is fulfilled. As can be seen in Table I, the $T_{1 \mathrm{C}}$ of the methyl carbon increases from $1.6 \mathrm{~s}$ to $2.7 \mathrm{~s}$ and $4.4 \mathrm{~s}$ as the temperature increases from room temperature to 50 and $80^{\circ} \mathrm{C}$. In this aspect one of the authors ${ }^{17}$ has already reported a $T_{1 \mathrm{C}}$ for the methyl carbon of $0.6 \mathrm{~s}$ at $-20^{\circ} \mathrm{C}, 1.5$ $\mathrm{s}$ at $24^{\circ} \mathrm{C}$, and $4.9 \mathrm{~s}$ at $55^{\circ} \mathrm{C}$ for $n-\mathrm{C}_{27} \mathrm{H}_{56}$ of a high purity (see Figure 9 of Reference 17). These results, and those listed in Table I for PE 1000 , confirm that $T_{1 \mathrm{C}}$ of the methyl carbon of low molecular weight polyethylenes and $n$-alkanes increase with increasing temperature, i.e., with increasing molecular mobility. Hence, it is evident that the $T_{1 \mathrm{C}}$ of the methyl carbon under consideration here is in the range where the extremely narrowing condition is fulfilled.

It should be noted that the $T_{1 \mathrm{C}}$ of $1.6 \mathrm{~s}$, obtained at room temperature, is very close to the $1.5 \mathrm{~s}$ value reported for the methyl carbon of $n-\mathrm{C}_{27} \mathrm{H}_{56}{ }^{17}$ The latter $n$ alkane was reported to have a purity higher than $99.9 \%$ and to have a well ordered orthorhombic crystal structure at room temperature. This, and other $n$-alkanes form molecular crystals with paired methyl ends. Hence, 
motion at low temperatures is restricted in these concerted structures. It is of interest to compare the spinlattice relaxation times of the methyl end group of the $n$ alkane with that obtained for the low molecular weight polyethylene. The inability of the polymer to form molecular crystals leads to crystallites with more disordered surfaces than those of the end-paired surfaces of the $n$-alkane crystallite. ${ }^{2}$ Some molecular motions of the $\mathrm{CH}_{3}$, in addition to three fold random rotation of this end group, such as random rotations around the bonds connecting the $\beta$ - and $\gamma$-methylene carbons, that are restricted in the $n$-alkanes, may be possible in PE 1000 . Thus, one initially would have anticipated a longer $T_{1 \mathrm{C}}$ value for this carbon in the low molecular weight polymer. However, it is obvious, by the similarity of the $T_{1 \mathrm{C}}$ values, that the presence of a more disordered surface does not contribute appreciably to this quantity. It appears that the invariance in $T_{1 \mathrm{C}}$ with respect to that of the methyl group in the $n$-alkane, is a consequence of the domination of the rotation around the three-fold axis of this end-group. As temperature is increased the methyl $T_{1 \mathrm{C}}$ increases to $2.7 \mathrm{~s}$ at $50^{\circ} \mathrm{C}$ and $4.4 \mathrm{~s}$ at $80^{\circ} \mathrm{C}$ due to the increase of molecular motion in the vicinity of molecular ends. However, as previously discussed, the mode of motion is predominantly the free rotation of the methyl group.

An interesting comparison can be made between the $T_{1 \mathrm{C}}$ of the methyl carbon and those that are either located in a side chain or are bonded to a methine carbon in the main chain. A $T_{1 \mathrm{C}}$ of $0.1 \mathrm{~s}$ is reported for the methyl carbon of the ethyl-branch of hydrogenated poly(butadiene). ${ }^{18}$ Saito et al. reported a $T_{1 \mathrm{C}}$ of $0.29 \mathrm{~s}$ at room temperature for the methyl carbon that is bonded to the methine carbon in the main chain of isotactic poly(propylene) in the noncrystalline environment. ${ }^{19}$ This value increases with temperature. The $T_{1 \mathrm{C}}$ of $1.6 \mathrm{~s}$ for the molecular end methyl carbon of PE 1000 is significantly longer than that of methyl carbon in either the side group or bonded to the methine carbon. This implies an enhanced motion of the molecular end methyl carbon due to the three-fold rotational motion of the molecular end methyl group of the polymer. In summary, the molecular motion of the methyl group of this PE sample in extended molecular chain form is relatively restricted as it is the methyl carbon of a highly ordered crystalline $n$ paraffin such as $n-\mathrm{C}_{27} \mathrm{H}_{56}$. Nevertheless, the motion is enhanced if compared with methyl carbons that are either in side branches or directly attached to the main chain.

$\alpha$-Methylene Carbon. The $T_{1 \mathrm{C}}$ of the downfield resonance of the $\alpha$-methylene carbon is $3.9 \mathrm{~s}$ at room temperature. This $T_{1 \mathrm{C}}$ value is in the range reported by Russell et al. ${ }^{11}$ These authors reported $4.8 \mathrm{~s}$ and $7.1 \mathrm{~s}$ for the $T_{1 \mathrm{C}}$ of the two low molecular weight polyethylenes that they studied. However, this $T_{1 \mathrm{C}}$ value of $3.9 \mathrm{~s}$ is much shorter than those reported ${ }^{11,17}$ for $n$-alkanes in the orthorhombic crystalline form. Russell, et al. reported $T_{1 \mathrm{C}}$ of $16 \mathrm{~s}$ and $20 \mathrm{~s}$, for $n-\mathrm{C}_{23} \mathrm{H}_{48}$ and $\mathrm{C}_{29} \mathrm{H}_{60}$ respectively. Kitamaru et al. ${ }^{17}$ reported a $T_{1 \mathrm{C}}$ of $53 \mathrm{~s}$ for $n-\mathrm{C}_{27} \mathrm{H}_{56}$. The difference between the $T_{1 \mathrm{C}}$ of the $\alpha$ methylene group in the $n$-alkanes and that of polyethylene reflects the disordered surface of the polymer crystallite. This disorder allows enhanced motions of groups in this region that are unavailable in the ordered crystalline array. Thus, methylene sequences of the polymer chain in the vicinity of the molecular ends, that are excluded from the crystal, may present random rotations around the bonds connecting $\alpha$ and $\beta$ methylene carbons and/or $\beta$ - and $\gamma$-methylene carbons, in addition to the three fold random rotation of methyl groups. In contrast, such molecular motions will be inhibited, except for the three-fold rotational motion of methyl groups, in the $n$-alkanes because of the well-ordered crystalline molecular alignment. As will be shown later the upfield resonance is negligible at temperatures below $30^{\circ} \mathrm{C}$.

The $T_{1 \mathrm{C}}$ value of $3.9 \mathrm{~s}$ for the $\alpha$-methylene carbon is rather long when compared with that of the internal methylene of polyethylene in the noncrystalline environment. A $T_{1 \mathrm{C}}$ of a few tenths of a second was reported for the internal methylene in both amorphous and crystalline-amorphous interphase of linear polyethylene. ${ }^{7}$ This large difference is related to the different molecular motion between the $\alpha$-methylene of the present sample and the internal methylene in the noncrystalline region of higher molecular weight polyethylenes. Although a disordered surface is clearly present in the extended low molecular weight crystallite, motion of methylene groups near the ends is more restricted than those in the liquid-like interlamellar region of the high molecular weight chain.

The temperature dependence of the $T_{\mathrm{IC}}$ of the $\alpha$ methylene carbon is somewhat complicated. The $T_{1 \mathrm{C}}$ of $3.9 \mathrm{~s}$ for the downfield resonance of the $\alpha$-methylene carbon at room temperature decreases to $3.7 \mathrm{~s}$ at $50^{\circ} \mathrm{C}$ and $2.5 \mathrm{~s}$ at $80^{\circ} \mathrm{C}$, whereas the $T_{1 \mathrm{C}}$ of $1.2 \mathrm{~s}$ for the upfield resonance at $50^{\circ} \mathrm{C}$ increases to $3.2 \mathrm{~s}$ at $80^{\circ} \mathrm{C}$. This opposite change with temperature indicates that the extremely narrowing condition is not fulfilled for the downfield resonance. However, it is fulfilled for the upfield one. Thus, both variations are in agreement with an increase mobility of this group with increasing temperature. The downfield resonance of $\alpha$-methylene carbon can be assigned to a population of less mobile $\alpha$ methylene groups, perhaps closer to the crystalline $\mathrm{CH}_{2}$, than those associated with the upfield line. A variation in the number of sequences in the disordered end-groups is expected from the heterogeneity of the length of the polymer molecules. The decrease of $T_{1 \mathrm{C}}$ of the less mobile $\alpha$ methylene groups with increasing temperature, $3.9 \mathrm{~s}$ to $2.5 \mathrm{~s}$, with a temperature increase to $80^{\circ} \mathrm{C}$ is not very large. This result shows that the mobility of the $\alpha$ methylene group is restricted by closeness to the crystalline $\mathrm{CH}_{2}$ component.

Phase Structure with Relation to Internal Methylene Carbons at Room Temperature as Revealed by Analysis of the Saturation-Recovery DD/MAS Spectrum

In an attempt to extract the conformational behavior of the molecular end groups we have initially examined the total phase structure of the sample by deconvoluting the line shape of the inner methylene carbons. For this purpose it is necessary to obtain the thermal equilibrium spectrum with relation to the inner methylene carbons. However, since it is difficult to obtain the equilibrium spectrum because of the very long $T_{1 \mathrm{C}}$, we attempted to extract the structure by measuring the 
Table II. Results of line deconvolution analysis of $100 \mathrm{~s}$ saturation-recovery spectrum at room temperature

\begin{tabular}{|c|c|c|c|c|}
\hline \multirow[b]{2}{*}{ Property } & \multicolumn{2}{|c|}{ Crystalline phase } & \multicolumn{2}{|c|}{ Noncrystalline phase } \\
\hline & Orthorhombic & $\begin{array}{c}\text { Monoclinic/ } \\
\beta \text {-methylene }^{\text {a }}\end{array}$ & $\begin{array}{l}\text { Less mobile } \\
\text { region }\end{array}$ & $\begin{array}{c}\text { More mobile } \\
\text { region }\end{array}$ \\
\hline Chemical shift/ppm & 32.4 & 33.8 & 31.7 & 29.9 \\
\hline Line width/Hz & 110 & 120 & 460 & 250 \\
\hline $\begin{array}{l}\text { Integral intensity } \\
\text { fraction }^{b}\end{array}$ & 0.785 & 0.037 & 0.135 & 0.042 \\
\hline $\begin{array}{l}\text { Corrected mass } \\
\text { fraction }\end{array}$ & 0.938 & 0.010 & 0.039 & 0.012 \\
\hline
\end{tabular}

saturation-recovery DD/MAS spectrum with a shorter recovery time. Thus, the ${ }^{13} \mathrm{C}$ magnetization that recovers in $100 \mathrm{~s}$ in the $\mathrm{B}_{0}$ direction after saturation was observed under ${ }^{1} \mathrm{H}$ DD. Figure 4 gives the $100 \mathrm{~s}$ saturation-recovery DD/MAS spectrum at room temperature in the range of internal methylene carbons as well as its lineshape deconvolution analysis. The spectral line is fitted to four Lorentzian distribution functions centered at $33.8,32.4,31.7$, and $29.9 \mathrm{ppm}$, respectively. The Lorentzians centered at $32.4,31.7$, and $29.9 \mathrm{ppm}$ are assigned to the orthorhombic crystalline phase, and regions of the disordered surface with different mobility. As mentioned previously, the Lorentzian component centered at 33.8 ppm is assigned either to the $\beta$ methylene carbon, the monoclinic crystalline methylene carbon or a linear combination of both. The composite curve that results from the four Lorentzian components reproduces the experimentally observed spectrum quite well. The results of this deconvolution are summarized in Table II.

Table II lists the integrated intensity fractions of each spectral component. These integrated intensity fractions do not indicate the true mass fraction of each phase in the crystalline polymer because the short delay time used, $100 \mathrm{~s}$, only allows one to detect the contributions from the orthorhombic components with shorter $T_{1 \mathrm{C}}$. However, the true mass fraction can be obtained from the orthorhombic contribution to the $32.4 \mathrm{ppm}$ line resonance, following the $100 \mathrm{~s}$ saturation-recovery pulse technique. The longitudinal magnetization evolves in the course of saturation-recovery as

$$
M_{z}(t)=M_{z}^{T_{1 \mathrm{c}}}\left[1-\exp \left(-t / T_{1 \mathrm{C}}\right)\right]
$$

where $M_{z}^{T_{\text {tr }}}$ is the longitudinal equilibrium magnetization of the component associated with a spin-lattice relaxation time of $T_{1 \mathrm{C}}$. Hence, the longitudinal magnetization from the orthorhombic crystalline component after $100 \mathrm{~s}$ of the saturation-recovery sequence is given as

$$
\begin{aligned}
M_{z}(100) & =M_{z}^{1500}[1-\exp (-100 / 1500)]+M_{z}^{390} \\
& \times[1-\exp (-100 / 390)]+M_{z}^{32}[1-\exp (100 / 32)] \\
& =0.065 M_{z}^{1500}+0.226 M_{z}^{390}+0.956 M_{z}^{32}
\end{aligned}
$$

Here, $M_{z}^{1500}, M_{z}^{390}, M_{z}^{32}$ denote the thermal equilibrium longitudinal magnetization of the orthorhombic crystal components with $T_{1 \mathrm{C}}$ of 1500,390 , and $32 \mathrm{~s}$, respectively as given in Table I. These magnetizations are given by the equilibrium magnetization of the entire orthorhombic crystalline component, $M_{Z}^{0}$, corrected by the fractional intensity of each component listed in Table I.

$$
\begin{aligned}
& M_{z}^{1500}=0.48 M_{z}^{0}, M_{z}^{390}=0.39 M_{z}^{0}, M_{z}^{32}=0.13 M_{z}^{0} \\
& \text { with } M_{z}^{1500}+M_{z}^{390}+M_{z}^{32}=M_{z}^{0}
\end{aligned}
$$

Inserting these values in eq 1 we have

$$
M_{z}(100) / M_{z}^{0}=0.244
$$

One can conclude that after $100 \mathrm{~s}$ at room temperature the magnetization centered at $32.4 \mathrm{ppm}$ recovers only to 0.244 of the total equilibrium value. Accordingly, the integral intensity fraction of the component centered at $32.4 \mathrm{ppm}$ in Table II must be multiplied by $1 / 0.244$ in order to obtain the true mass fraction of the orthorhombic crystalline phase. If it is assumed that the magnetization of the other components at 33.8,31.7, and $29.9 \mathrm{ppm}$ have completely recovered their equilibrium values at $100 \mathrm{~s}$, one can estimate the mass fraction of each phase. The corrected mass fractions that were obtained in this manner are shown in the last row of Table II. This mass fraction of the orthorhombic crystalline component is very high, 0.938 . It agrees, within the experimental error, to the value of 0.85 obtained from the heat of fusion.

High levels of the degree of crystallinity are characteristic of extended chain crystallites of low molecular weight polyethylenes and the $n$-alkanes, including those of comparable length. ${ }^{2,20}$ The disorder at the surface accounts for a small fractional content of noncrystalline component, 0.051 , of the structure. Within this disordered region, the less mobile methylenes closer to the crystal surface are distinguished by line-shape deconvolution procedures from those more mobile methylenes bounded to the methyl end groups. It is expected that the former accounts for a greater content based on the crystallite structure of this polymer and the nonhomogeneity of chain length.

Also included in Table II are the line widths of the inner methylene components. The $110 \mathrm{~Hz}$ line width of the orthorhombic component is appreciably wider than the values reported for the orthorhombic component of linear polyethylene ${ }^{7}$ or branched polyethylene. ${ }^{18}$ However, one needs to take into account the short delay time of the experiment. The component being considered is the less perfect crystalline component with $T_{1 \mathrm{C}}$ of $32 \mathrm{~s}$. The narrow component with $T_{1 \mathrm{C}}$ of $1500 \mathrm{~s}$ is only accounted up to $6.5 \%$ as indicated by eq 1 . For this reason the line widths of the methylenes in the disordered surface are wider than those reported for the noncrystalline regions of high molecular weight polyethylenes. ${ }^{7,18}$

Temperature Dependence of DD/MAS Spectra Obtained with 20 s Saturation-Recovery Spectra

A main objective of this work is to study the changes, if any, in conformational disorder at the surface of the crystallite with increasing temperature. Pre-melting or, 


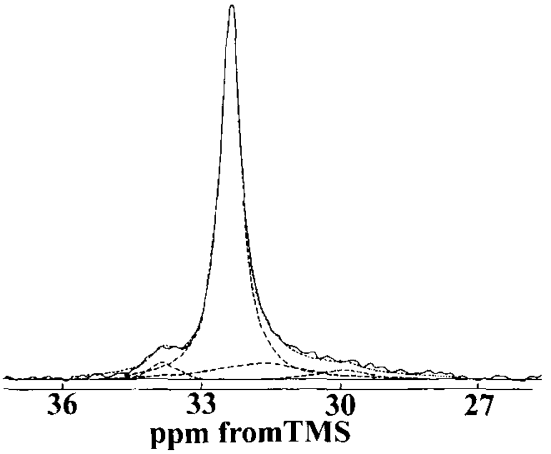

Figure 4. The $100 \mathrm{~s}$ saturation-recovery spectrum with line shape Lorentzian deconvolution analysis. Lorentzians centered at $32.4,31.7$, and $29.9 \mathrm{ppm}$ are assigned to the orthorhombic crystalline phase, and regions of the disordered surface with different mobility. Lorentzian component centered at $33.8 \mathrm{ppm}$ is assigned either to $\beta$ methylene carbon, the monoclinic crystalline methylene carbon or a linear combination of both.

the onset of conformational disorder, at the end-sequences of the molecule, prior to complete melting, was observed, by a variety of experimental techniques, in all the $n$-alkanes that have been studied..$^{1,2,20-22}$ The methods include nmr, vibrational spectroscopy and thermal analysis among others. A polydisperse low molecular weight polyethylene has also been reported to show conformational disordering of the terminal chain segments at temperatures well below complete melting. ${ }^{20}$ However DD/MAS solid-state NMR studies were only carried out at room temperature and at $87^{\circ} \mathrm{C}$. Thus, the onset of premelting, and its extent in comparison to that observed in the molecular crystals formed by the $n$-alkanes of comparable chain lengths could not be assessed. In order to examine the problem in detail, partially relaxed DD/MAS spectra were examined for PE 1000 over a large temperature range. The very long $T_{1 \mathrm{C}}$ values in the crystalline region prevent the collection of spectra corresponding to the fully equilibrated structure. Thus, motional changes of the internal methylene carbons close to the surface, or the ends, were followed, as a function of temperature, by analyzing the DD/MAS spectra after a $20 \mathrm{~s}$ saturation-recovery. According to the $T_{1 \mathrm{C}}$ data listed in Table I, only the fast relaxing fraction of the internal crystalline methylenes relaxes during this time. Therefore, the results are of partially relaxed spectra. These spectra are shown in Figure $4 a$ for the region of resonance of the internal methylenes. Figure $5 \mathrm{~b}$ shows similar spectra in the region of the end-methyl and $\alpha$ methylene carbons. This figure makes clear that the lineshapes of the methyl and $\alpha$-methylene carbons change continuously and significantly with increasing temperature. In contrast, the lineshape of the crystalline methylenes, centered at $32.4 \mathrm{ppm}$, does not change appreciably up to temperatures of $60^{\circ} \mathrm{C}$.

We first consider in more detail the temperature dependence of the spectrum for the $\alpha$-methylene and methyl carbons (Figure 5b). As is indicated in Table I, the $T_{1 \mathrm{C}}$ of the $\alpha$-methylene and methyl carbons are much shorter than $20 \mathrm{~s}$ of the recovery time in all temperature range examined. Thus, Figure $5 \mathrm{~b}$ represents the thermal equilibrium spectra for these carbons. At $30^{\circ} \mathrm{C}$ the resonances that correspond to the $\alpha$-methylene
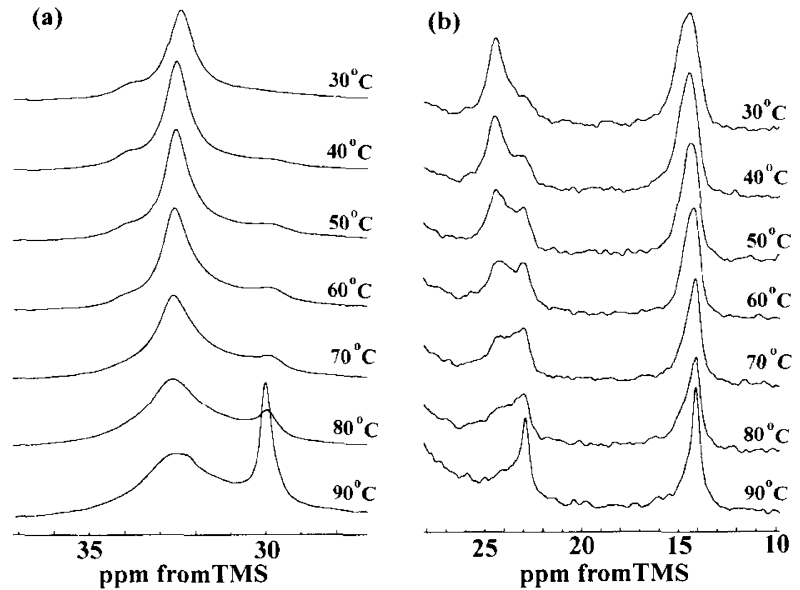

Figure 5. $20 \mathrm{~s}$ saturation-recovery VTDD/MAS spectra at the indicated temperatures. (a) Internal methylene region. (b) The endgroup methyl carbon and the $\alpha$-methylene carbon regions. Temperatures studied are indicated.

and methyl carbons are in the range of $22-27$ and $13-$ $17 \mathrm{ppm}$, respectively. The former clearly consists of two overlapping resonances. The upfield one is associated with $\alpha$-methylene carbons that have higher mobility. With increasing temperature the intensity of the upfield line increases and the downfield resonance intensity decreases with temperature. The more mobile $\alpha$-methylenes can be identified with those associated with the disordered sequences at the chain ends. As stated above there is a continuous increase in their concentration with temperature, while at least up to $60^{\circ} \mathrm{C}$, the concentration of the internal methylene does not change.

At $90^{\circ} \mathrm{C}$ the linewidth of the upfield methylene resonance becomes very narrow indicative of a significant change in mobility. The downfield resonance is now barely perceptible. The thermogram in Figure 1 indicates that the polymer is well into the melting range at this temperature. There is also a shoulder at about $95^{\circ} \mathrm{C}$ to the main endotherm that is located at $105^{\circ} \mathrm{C}$. One can conclude that even at temperatures before the onset of fusion, at about $70^{\circ} \mathrm{C}$, there is a significant enhanced mobility of the $\alpha$-methylene carbons. This mobility results from disordering the end-sequences.

Splitting was also observed for the methyl resonance in the $13-17 \mathrm{ppm}$ region in the CP/MAS spectrum shown in Figure 2. However, splitting is not observed in this DD/MAS spectrum of Figure $4 \mathrm{~b}$ for the methyl group. Here only linewidth narrowing and an upfield shift are recognized with increasing temperature. This is consistent with an increase in gauche conformers that are clearly shown at temperatures above $60^{\circ} \mathrm{C}$. The temperature at which conformational disorder at the surface becomes detectable by this probe is, by examination of the thermogram in Figure 1, well below the temperature at which the actual melting starts.

In analyzing the spectra of the internal methylene carbons, Figure $5 \mathrm{a}$, it should be pointed out again that these spectra only involve the resonances with relation to the magnetization that longitudinally recovers within $20 \mathrm{~s}$. For example in the spectrum obtained at $30^{\circ} \mathrm{C}$ only a fraction of the crystalline methylenes associated with a $T_{1 \mathrm{C}}$ of $32 \mathrm{~s}$ will be included. However, all the noncrystalline methylenes will be included in this spectrum 
since their $T_{1 \mathrm{C}}$ is much less than $20 \mathrm{~s}$. The linewidth at $30^{\circ} \mathrm{C}$ of the resonance centered at $32.4 \mathrm{ppm}$ is rather broad indicating that the molecular conformation of the crystalline part detected is somewhat distorted. At $30^{\circ} \mathrm{C}$ the resonance at $c a$. $30 \mathrm{ppm}$, that is assigned to noncrystalline amorphous methylene carbon is not resolved. It is detected at $40^{\circ} \mathrm{C}$ and a distinct peak is observed at temperatures of $60^{\circ} \mathrm{C}$ and higher. Interestingly, the line shape of the crystalline methylenes that are centered at $32.4 \mathrm{ppm}$, broadens appreciably at temperatures higher than $60^{\circ} \mathrm{C}$. Recognizing the crystalline methylenes represented by the spectra shown in Figure $5 \mathrm{a}$ are those that are preferentially close to or on the surface of the crystallite, the observed changes indicate that disordering or pre-melting takes place at temperatures as low as $40^{\circ} \mathrm{C}$. The disordering process becomes concerted at temperatures close to $60^{\circ} \mathrm{C}$. The fact that the $32.4 \mathrm{ppm}$ resonance does not show lineshape changes up to temperatures of approximately $60^{\circ} \mathrm{C}$ also indicates that enhanced conformational disorder takes place in the carbons in the vicinity of the molecular-ends before any appreciable conformational change is observed for the inner methylene ones. At $90^{\circ} \mathrm{C}$ the $32.4 \mathrm{ppm}$ resonance seems to split into two broad components. There is also an increase in the noncrystalline resonance at ca. 30 ppm. The higher field component will have a contribution from a crystalline component whose molecular mobility increases with temperature, while maintaining the orthorhombic crystalline form.

\section{CONCLUSIONS}

A detailed analysis of the solid-state carbon-13 NMR spectrum of extended chain crystallites formed by a low molecular weight polyethylene fraction revealed the presence of three regions of methylene carbons, each with a different mobility. There are the crystalline region and two regions of different mobility in the noncrystalline disordered surface. These regions are a consequence of the heterogeneity of molecular lengths, even for a good fraction, and that the ends are not paired in these crystallites. Thus, the onset of conformational disordering of sequences at the ends of the molecule, takes place at relatively low temperatures. This conclusion is in accord with the structural model that has been taken for an equilibrium crystallite. ${ }^{3}$ These changes were followed by VT DD/MAS spectra collected in a wide temperature range. An increase in concentration of disor- dered methylene groups was observed at temperatures as low as $40^{\circ} \mathrm{C}$. In these type crystals the onset of premelting occurs at lower temperatures than those for the premelting observed in molecular crystals of $n$ alkanes of comparable chain length.

Acknowledgment. Support of the work at Florida State University by the National Science Foundation Polymer Program (DMR 94-19508) and at Florida Agricultural and Mechanical University by NSF, POWRE Program (DMR 9753258) is gratefully acknowledged.

\section{REFERENCES}

1. L. Mandelkern, R. G. Alamo, and D. L. Dorset in "Acta Chimica Hungarica-Models in Chemistry", A. P. Schubert, Ed., Akademiai Kiado, Budapest, 1993, p 415.

2. L. Mandelkern, A. Prasad, R. G. Alamo, and G. M. Stack, Macromolecules, 23, 3696 (1990).

3. P. J. Flory and A. Vrij, J. Am. Chem. Soc., 85, 3548 (1963).

4. T. Asahi, J. Polym. Sci., Polym. Phys. Ed., 22, 175 (1984).

5. M. L. Kaplan, F. A. Bovey, and H. N. Cheng, Anal. Chem., 47, 1703 (1975).

6. R. H. Glaser and L. Mandelkern, J. Polym. Sci., Polym. Phys. Ed., 26, 221 (1988).

7. R. Kitamaru, F. Horii, and K. Murayama, Macromolecules, 19, 636 (1986).

8. W. L. Jarrett, L. J. Mathias, R. G. Alamo, L. Mandelkern, and L. D. Douglas, Macromolecules, 25, 3468 (1992).

9. K. Takamizawa, Y. Ogawa, and T. Oyama, Polym. J., 14, 441 (1982).

10. E. Pérez and D. L. VanderHart, J. Polym. Sci., Polym. Phys. Ed., 25, 1637 (1987).

11. K. R. Russell, S. B. Gang Wu, and R. D. Heyding, Polymer, 33, 951 (1992)

12. D. L. VanderHart and E. Pérez, Macromolecules, 25, 1902 (1986).

13. D. A. Torchia, J. Magn. Reson., 30, 613 (1978).

14. B. Schröter and A. Posern, Makromol. Chem., Rapid Commun., 3, 623 (1982).

15. E. Pérez, D. L. VanderHart, B. Crist, and P. R. Howard, Macromolecules, 20, 78 (1987).

16. D. E. Axelson, L. Mandelkern, R. Popli, and P. Mathieu, J. Polym. Sci., Polym. Phys. Ed., 21, 2319 (1983).

17. R. Kitamaru, F. Horii, M. Nakagawa, K. Takamizawa, Y. Urabe, and Y. Ogawa, J. Molecular Structure, 355, 95 (1995).

18. R. Kitamaru, T. Nakaoki, R. G. Alamo, and L. Mandelkern, Macromolecules, 29, 6847 (1996).

19. S. Saito, Y. Moteki, M. Nakagawa, F. Horii, and R. Kitamaru, Macromolecules, 23, 3256 (1990).

20. M. Möller, H.-J. Cantow, H. Drotloff, D. Emeis, K.-S. Lee, and G. Wegner, Makromol. Chemie., 187, 1237 (1986).

21. W. L. Jarrett, L. J. Mathias, R. G. Alamo, L. Mandelkern, and D. L. Dorset, Macromolecules, 25, 3468 (1992).

22. M. Maroncelli, H. L. Strauss, and R. G. Synder, J. Chem. Phys., 82, 2811 (1985). 